\title{
Towards SunSmart school policies in South Africa
}

AUTHORS:

Caradee Y. Wright ${ }^{1}$

Anthony J. Mundackal2

Maria A. Oosthuizen 1

Patricia N. Albers ${ }^{3}$

\section{AFFILIATIONS:}

${ }^{1}$ Climate Studies, Modelling and Environmental Health Research Group, Council for Scientific and Industrial Research, Pretoria, South Africa

${ }^{2}$ Physiology and Environmental Health, University of Limpopo,

Polokwane, South Africa

${ }^{3}$ Environment and Health Research Unit, South African Medical Research Council, Johannesburg, South Africa

\section{CORRESPONDENCE TO: \\ Caradee Wright}

EMAIL:

cwright@csir.co.za

\section{POSTAL ADDRESS:}

Climate Studies, Modelling and Environmental Health Research Group, Council for Scientific and Industrial Research, P0 Box 395, Pretoria 0001, South Africa

\section{KEYWORDS:}

policy; school; sun protection; schoolchildren; public health

\section{HOW TO CITE:}

Wright CY, Mundackal AJ, Oosthuizen MA, Albers PN. Towards SunSmart school policies in South Africa. S Afr J Sci. 2014;110(9/10), Art. \#0078, 4 pages. http://dx.doi. org/10.1590/sajs.2014/a0078

(C) 2014. The Authors. Published under a Creative Commons Attribution Licence.
Solar ultraviolet radiation exposure is the major cause of cancers of the skin and cataracts of the eyes. Skin cancer rates in South Africa, particularly among white individuals, are among the highest in the world. Moreover, recent data have raised new concerns about increasing non-melanoma skin cancer incidence among black South Africans who are HIV positive. ${ }^{1,2}$ Cataracts are the leading cause of blindness in South Africa. ${ }^{3}$ Prevention of these adverse health effects requires an appropriate behavioural response in the form of sun protection. Sunscreen, clothing, hats, umbrellas and shade structures offer varying degrees of photoprotection against excess personal solar ultraviolet radiation exposure. Schools have an important part to play in supporting children to make healthy sun choices. The International Community Preventive Services Task Force released a statement that supported 'strong evidence' for the effectiveness of interventions in primary schools aimed at the prevention of skin cancer that combine education and policy approaches to increase preventive behaviours, specifically, child sun protective practices that reduce sunburn incidence and new melanocytic mole development. ${ }^{4}$

In South Africa, more than 10 million schoolchildren attend government schools on a daily basis. To date, sun protection has not been a top priority at schools; pressing issues such as nutrition and violence have taken precedence. However, if we wish to curtail skin cancer incidence rates, interventions in schools seem to be a reasonable place to start. Hence, a study to assess schools' sun-related efforts and schoolchildren's sun-related knowledge, attitudes and behaviours was carried out among 24 urban government primary schools in 2012 . Not one school had a sun protection policy in place ${ }^{5}$; however, several children knew about the need for sun protection and some practised positive sun behaviours. ${ }^{6}$ An opportunity then arose to survey children attending a government primary school in KwaZulu-Natal that implemented a sun protection policy in 2013 with the identical instrument and then compare their questionnaire results to the previous results. Here, we report on the findings of this comparison. While the results are not meant to be representative of South Africa, they raise some interesting questions and support the need for further research.

\section{Methods}

\section{Study design}

This study was designed as a cross-sectional, descriptive epidemiological study. The study took place during the third South African school term (August-October 2012) at the end of winter / beginning of spring (field research is usually not permitted in the fourth school term according to the prescribed requirements of the Provincial Departments of Education). Self-completed questionnaires were issued to Grade 7 learners at schools randomly selected in all nine South African provinces. Once the sample was defined, school principals were contacted and invited to participate. When a school chose not to participate, the next randomly selected school from the same province was contacted until the total of 24 schools was reached. Ethical clearance for this study was obtained from the Research Ethics Committee of the Council for Scientific and Industrial Research (35/2012) on 27 June 2012. Provincial approval was obtained from all nine provinces. School principals gave informed consent for the study prior to contacting the children. Children's parents/guardians/caregivers completed an informed consent form and children gave assent prior to completing the questionnaire.

\section{Study sample and comparison school}

A total of 36 schools, four from each province, were invited to participate in the study, but only 24 schools did participate. This number was determined based on the project budget and the cost of couriering questionnaires to and from schools throughout South Africa. Schools were randomly selected from the Department of Basic Education schools database. Schools were eligible for inclusion in the study if they had a Grade 7 class of children (modal age 13 years), they were public schools and they were situated in an urban setting (rural schools were excluded due to access constraints). Co-educational schools at which either English or Afrikaans was the main spoken and written language were included. Private schools, correspondence, home schools and schools for children with special needs were excluded because they require a different research methodology. Schools with Grade 7 classes with fewer than 10 children were excluded to optimise the study budget. The school with a sun policy was purposefully selected for comparison purposes based on the following criteria: it had a sun policy in place, it had Grade 7 classes with more than 10 learners, it was an urban school and English or Afrikaans was the main language of the learners.

\section{Questionnaire}

The questionnaire administered to the children was based on previously tested and validated instruments $\mathrm{s}^{7,8}$ and adapted for local cultural differences (for example, a question was added on skin bleaching). Four general sections were included: (1) attitudes towards sun exposure, suntanning and sun protection; (2) knowledge of the impacts of the sun and sun protection; (3) outdoor sun protection behaviour; and (4) demographic data. The questionnaire was piloted, translated (into Afrikaans) and posted to all schools with the information sheets and consent forms.

\section{Statistical analyses}

All questionnaire data were coded and entered into an electronic database (double data entry). These data were then prepared and imported into Stata 11.0 statistical analysis software. Descriptive statistics including observed frequencies for all variables were calculated. 


\section{Results}

Table 1 provides the descriptive statistics for the two samples, i.e. children at a school $(n=1)$ with a sun policy and children at schools $(n=24)$ without a sun policy. At the school with a sun policy, there were equal numbers of girls and boys; most children were 12 years old, and most self-reportedly belonged to the white ethnic group and had white or light brown skin. For the children attending the 24 schools with no sun policies, there were more girls than boys; most children were 13 years old and most self-reportedly belonged to the black ethnic group with self-reported light brown or brown skin on the unexposed, inner upper arm. The age difference was likely as a result of the time of year when the Grade 7 learners were asked to complete the questionnaire. At the school with the sun policy, the learners completed the questionnaire early in the year (in February 2014), whereas the learners at the schools without sun policies completed the questionnaire in the later part of the year (in August 2012).

The frequencies of responses for each questionnaire item for children attending the school with a policy and children attending schools without policies are given in Table 2. For most questions, the percentages of responses were similar for the two groups. This was the case for behaviour questions: sunbathing regularly, not applying fake tanning or skin lightening cream; staying in the shade; wearing a hat or cap; wearing a broad-brimmed hat, bucket hat or cap with flaps; and wearing clothing. It was also the case for the following attitude questions: feeling healthier with a suntan; agreeing that friends think a suntan is a good thing; agreeing that family think a suntan is a good thing; agreeing that tanned or dark skin protects against skin cancer; agreeing that a suntan is less fashionable now than it used to be; agreeing that clothing that covers most of the arms and legs is not fashionable; and agreeing that there is little chance that I will get skin cancer. Similarly, the percentage of responses was the same for both samples for knowledge questions, including agreeing that it is safe to get sunburnt once or twice a year.

In terms of sun-related behaviours, more learners attending the school with a sun policy reportedly got a suntan last summer, did not use oils or lotions to get a suntan, used sunscreen and were sunburnt last summer than learners attending schools without sun policies. More children at the school with a policy also tended to know about the things one can do to try and avoid skin cancer, including avoiding getting sunburnt, staying out of the summer sun, covering up with clothing and using sunscreen. Compared with learners attending schools without sun policies, more children at the school with a policy knew that melanoma was a form of skin cancer, had seen or heard about the ultraviolet index and had heard about the Cancer Association of South Africa.

\section{Discussion}

In general, children attending the school that had a sun policy tended to know more about sun protection and skin cancer, to practise safe sun behaviours more often and to have healthier sun-related attitudes compared with children attending schools without sun policies in place. This finding is positive; however, we did not test our findings for statistically significant differences, mainly because of the skewed sample sizes (i.e. 82 versus 707 ) and different ethnic composition of the two study groups, and the results need to be verified with data from additional government primary schools that do have a sun policy in

Table 1: $\quad$ Sample demographics

\begin{tabular}{|c|c|c|}
\hline & $\begin{array}{c}\text { Children attending a school with a } \\
\text { sun policy } \\
\%(n)\end{array}$ & $\begin{array}{c}\text { Children attending the } 24 \text { schools } \\
\text { without a sun policy } \\
\%(n)\end{array}$ \\
\hline Number of learners & (82) & (707) \\
\hline \multicolumn{3}{|l|}{ Gender } \\
\hline Male & $50.0(41)$ & $38.0(269)$ \\
\hline Female & $50.0(41)$ & $61.3(434)$ \\
\hline Not disclosed & $0(0)$ & $0.5(4)$ \\
\hline \multicolumn{3}{|l|}{ Age } \\
\hline 11 years old & $6.1(5)$ & $0.8(6)$ \\
\hline 12 years old & $62.2(51)$ & $24.4(173)$ \\
\hline 13 years old & $31.7(26)$ & $60.6(429)$ \\
\hline Other & $0(0)$ & $13.7(97)$ \\
\hline Not disclosed & $0(0)$ & $0.2(2)$ \\
\hline \multicolumn{3}{|c|}{ Ethnic group (self-reported, children could belong to more than one group) } \\
\hline Black & $14.1(12)$ & $39.7(312)$ \\
\hline Indian/Asian & $14.1(12)$ & $7.52(59)$ \\
\hline White & $68.2(58)$ & $26.6(209)$ \\
\hline Coloured & $2.35(2)$ & $22.5(177)$ \\
\hline Other & $1.17(1)$ & $1.7(14)$ \\
\hline Don’t know & $0(0)$ & $1.6(13)$ \\
\hline \multicolumn{3}{|c|}{ Skin colour (self-reported) } \\
\hline White & $39.0(32)$ & $21.5(152)$ \\
\hline Light brown & $48.7(40)$ & $54.3(384)$ \\
\hline Brown & $10.9(9)$ & $15.5(107)$ \\
\hline Dark brown & $0(0)$ & $5.9(42)$ \\
\hline Black & $1.2(1)$ & $2.6(19)$ \\
\hline Not disclosed & $0(0)$ & $0.4(3)$ \\
\hline
\end{tabular}


Table 2: Comparison of frequencies of responses to all questionnaire items between children at a school with a sun policy and children at schools without sun policies

\begin{tabular}{|c|c|c|}
\hline Questionnaire item & $\begin{array}{l}\text { Children at a school with a sun policy } \\
\qquad \%(n)\end{array}$ & $\begin{array}{l}\text { Children at schools without a sun policy } \\
\qquad \%(n)\end{array}$ \\
\hline Got a suntan last summer & $75.6(62)$ & $59.4(420)$ \\
\hline Sunbathed regularly to get a suntan & $18.2(15)$ & $21.7(154)$ \\
\hline Did not use oils or lotions to get a suntan & $87.8(72)$ & $68.7(486)$ \\
\hline Did not apply a fake tanning lotion & $100.0(82)$ & $90.1(637)$ \\
\hline Never used a sunbed & $98.7(81)$ & $93.7(663)$ \\
\hline Got sunburnt last summer & $82.9(68)$ & $56.0(396)$ \\
\hline \multicolumn{3}{|l|}{ To protect yourself from getting sunburnt, did you ever: } \\
\hline Stay inside & $86.5(71)$ & $72.4(512)$ \\
\hline Stay in the shade & $89.0(73)$ & $85.9(608)$ \\
\hline Wear a hat or cap & $78.0(64)$ & $72.0(509)$ \\
\hline Wear a broad-brimmed hat, bucket hat or cap with flaps & $45.1(37)$ & $49.3(349)$ \\
\hline Wear clothing (not a hat) & $60.9(50)$ & $53.7(380)$ \\
\hline Use sunscreen & $90.2(74)$ & $65.7(465)$ \\
\hline Applied a skin lightening cream & $3.6(3)$ & $18.5(131)$ \\
\hline Feel healthier with a suntan & $4.8(4)$ & $8.4(60)$ \\
\hline Feel more attractive with a suntan & $28.0(23)$ & $17.1(121)$ \\
\hline Friends think a suntan is a good thing & $18.2(15)$ & $15.9(113)$ \\
\hline Family think a suntan is a good thing & $18.2(15)$ & $14.1(100)$ \\
\hline Tanned or dark skin protects you against skin cancer & $3.6(3)$ & $9.7(69)$ \\
\hline Having a tan is less fashionable now than it used to be & $18.2(15)$ & $19.9(141)$ \\
\hline $\begin{array}{l}\text { Clothing which covers most of the arms and legs is } \\
\text { not fashionable }\end{array}$ & $21.9(18)$ & $23.0(163)$ \\
\hline There is little chance that I will get skin cancer & $25.6(21)$ & $27.8(197)$ \\
\hline It is safe to get sunburnt once or twice a year & $30.4(25)$ & $22.3(158)$ \\
\hline \multicolumn{3}{|l|}{ Things you can do to not get skin cancert: } \\
\hline Avoid getting sunburnt & $91.4(75)$ & $64.4(456)$ \\
\hline Stay out of the summer sun & $73.1(60)$ & $48.0(340)$ \\
\hline Cover up with clothing & $68.2(56)$ & $45.5(322)$ \\
\hline Use sunscreen & $96.3(79)$ & $65.4(463)$ \\
\hline Get a suntan & $3.6(3)$ & $5.2(37)$ \\
\hline Go to a sunbed clinic & $2.4(2)$ & $14.9(106)$ \\
\hline Eat the rights foods & $32.9(27)$ & $38.0(269)$ \\
\hline Melanoma is a form of skin cancer & $25.6(21)$ & $13.4(95)$ \\
\hline Seen or heard about the ultraviolet index & $64.6(53)$ & $28.5(202)$ \\
\hline Heard about CANSA & $86.5(71)$ & $74.4(526)$ \\
\hline
\end{tabular}

+Note: children could choose more than one response. 
place. This verification is currently difficult to achieve because very few government primary schools have adopted sun protection policies, but we expect that this situation will change in the next 5 to 10 years.

The most striking result was found in responses from children at the school with a sun policy compared with children at schools without sun policies: more of the former reported getting sunburnt in the last summer than the latter. At first, one would consider this finding surprising and deem it a failure of the school sun policy and implemented activities. But, upon reflection, this result probably shows that more children at the school with a sun policy are aware of the dangers of the sun and of the risk of sunburn as they have been educated about it at school. Therefore, it is possible that they would better remember any occurrence of sunburn, however mild or severe, than would the children at schools without sun policies. It might also reflect the skin photosensitivity of the children at the school with a sun policy (being mostly fair-skinned individuals) and their increased susceptibility to sunburn compared with children with darker skin. There may also be a component of the Hawthorne effect, whereby the children answered in the way that they thought they were expected to answer, an extremely difficult effect to resolve. There may also have been under-reporting by learners at schools without sun policies when asked about experiencing sunburn because learners did not understand what sunburn is, despite perhaps having experienced it. The timing of the questionnaire survey may also have influenced the results (i.e. end of summer at the school with a policy versus end of winter at the schools without sun policies), causing the recall period to be much longer for the schools without a sun policy compared to the school with a sun policy. An attempt must be made to resolve all of these issues in future studies.

Few studies have considered whether having a school sun policy results in children with greater knowledge, more positive attitudes and healthy behaviours in terms of sun protection. One recent Australian, ecological study considered whether being a SunSmart school (a school with a sun policy) influenced hat-wearing compliance. They found that SunSmart status was not consistently associated with better hat-wearing behaviour (in terms of type of hat and frequency of hat wearing). ${ }^{9}$ Their sample size was in excess of 30000 children and teachers, highlighting the importance of increasing our sample size for future research to augment our findings.

\section{Conclusions}

This first glimpse at the possible impact that a school sun protection policy may have on schoolchildren suggests that schools may play an important role in increasing learner knowledge about sun protection and skin cancer. However, there are many other important factors, besides school support, that will need to be considered to change learners' behaviours and attitudes in relation to sun exposure. A holistic approach to sun awareness and safe sun practices - involving school, family, government and community - is most likely needed to ensure safe sun behaviour and reduce the adverse health impacts of excess sun exposure.

\section{References}

1. Norval M, Kellet P, Wright CY. The incidence and body site of skin cancers in the population groups of South Africa. Photoderm Photoimmunol Photomed. Forthcoming 2014. http://dx.doi.org/10.1111/phpp.12106

2. Silverberg MJ, Leyden W, Warton EM, Quesenberry CP, Engels EA, Asgari MM. HIV infection status, immunodeficiency, and the incidence of nonmelanoma skin cancer. J Natl Cancer Inst. 2013;105(5):350-360. http:// dx.doi.org/10.1093/jnci/djs529

3. Lecuona K, Cook C. South Africa's cataract surgery rates - Why are we not meeting our targets? S Afr Med J. 2011;101(8):510-512.

4. Saraiya M, Glanz K, Briss PA, Nichols P, White C, Das D. Interventions to prevent skin cancer by reducing exposure to ultraviolet radiation: A systematic review. Am J Prev Med. 2004;27(5):422-426.

5. Wright CY, Albers PN, Oosthuizen MA, Phala N. Sun protection policy and practices in South African primary schools. Household and Personal Care Today Monographic Supplement Series. 2013;8(4):iv-viii.

6. Wright CY, Albers PN, Oosthuizen MA, Phala N. Self-reported sun-related knowledge, attitudes and behaviours among schoolchildren attending South African primary schools. Photoderm Photoimmunol Photomed. Forthcoming 2014. http://dx.doi.org/10.1111/phpp.12107

7. Tempark T, Chatproedprai S, Wananukul S. Attitudes, knowledge and behaviours of secondary school adolescents regarding protection from sun exposure: A survey in Bangkok, Thailand. Photoderm Photoimmunol Photomed. 2012;28(4):200-206.

8. Wright C, Reeder A, Gray A, Cox B. Child sun protection: Attitudes mediate the association between children's knowledge and behaviours. J Paediatr Child Health. 2008;44:692-698. http://dx.doi.org/10.1111/j.1440-1754. 2008.01408.x

9. Turner D, Harrison SI, Buettner P, Nowak M. Does being a "SunSmart School" influence hat-wearing compliance? An ecological study of hat-wearing rates at Australian primary schools in a region of high sun exposure. Prev Med. 2014;60:107-114. http://dx.doi.org/10.1016/j.ypmed.2013.12.020 